Hydrol. Earth Syst. Sci., 17, 691-704, 2013

www.hydrol-earth-syst-sci.net/17/691/2013/

doi:10.5194/hess-17-691-2013

(C) Author(s) 2013. CC Attribution 3.0 License.

\title{
Mesoscale connectivity through a natural levee
}

\author{
A. E. Newman and R. F. Keim \\ Louisiana State University Agricultural Center, School of Renewable Natural Resources, Baton Rouge, LA 70803, USA
}

Correspondence to: A. E. Newman (anewma9@tigers.lsu.edu)

Received: 11 April 2012 - Published in Hydrol. Earth Syst. Sci. Discuss.: 19 June 2012

Revised: 12 December 2012 - Accepted: 22 January 2013 - Published: 15 February 2013

\begin{abstract}
Natural levees are potentially locally important zones of lateral seepage between stream channels and floodplain backswamps, because their relatively coarser soils provide pathways of high hydraulic conductivity in an otherwise low conductivity system. Therefore, understanding the rates and mechanisms of subsurface exchange of water and solutes through natural levees may be necessary for understanding biogeochemical cycling in floodplains. We measured imposed hydraulic gradients and solute tracers in 19 shallow monitoring wells within a $580 \mathrm{~m}^{3}$ volume of natural levee in the Atchafalaya Basin, Louisiana. We modeled residence time distributions of pressure and tracers using a simple linear system to quantify spatially variable transport velocities and infer dominant flow mechanisms at a mesoscale. The spatial mean velocity of pressure transport was faster than the mean velocity of tracer transport by two orders of magnitude $\left(1.7 \times 10^{-2}\right.$ and $4.6 \times 10^{-4} \mathrm{~m} \mathrm{~s}^{-1}$, respectively), and the variance of pressure velocities was less than the variance of tracer velocities by seven orders of magnitude $\left(1.4 \times 10^{4} \mathrm{~min}^{2}\right.$ and $7.9 \times 10^{11} \mathrm{~min}^{2}$, respectively). Higher spatial variability of tracer velocities compared to pressure velocities indicates different functioning mechanisms of mass versus energy transport and suggests preferential flow. Effective hydraulic conductivities, which ranged in magnitude from $10^{-1}$ to $10^{3} \mathrm{~m} \mathrm{~d}^{-1}$, were higher than would be predicted by soil texture. We conclude that, in this fine-grained system, preferential flow paths control water and solute exchange through natural levees. These findings are important for future studies of water and solute cycling in riverine wetlands, and rates of exchange may be particularly useful for modeling water and nutrient budgets in similar systems.
\end{abstract}

\section{Introduction}

\subsection{Background}

In floodplains, water exchange between river channels and adjacent wetlands influences hydrologic functions and associated ecosystem services (Sabo et al., 1999; Amoros and Bornette, 2002; Malard et al., 2002), but the rate of exchange (i.e., connectivity) is difficult to quantify. In many riverine wetlands, natural levees, which form as rivers deposit coarse sediments adjacent to the channel during overbank flow, are physical barriers to surface exchange between river channels and adjacent low-lying backwater areas. Because natural levees form during high-flow events, their soil texture is coarser than adjacent backswamp deposits (Cazanacli and Smith, 1998); in combination with the inherently layered structure, this makes natural levees potentially locally important zones of lateral seepage by providing pathways of high hydraulic conductivity in an otherwise low conductivity system. Such connectivity between backswamp wetlands and stream channels has important implications for biogeochemical processes (Johnston, 2001) and thus for water quality. The effectiveness of floodplains in processing pollutants such as excess nutrients depends on exchange between rivers and wetlands (Rassam et al., 2006). These exchange processes depend greatly on the permeability of soils in the channel's bed and banks, hydraulic gradients, and channel morphology (Malard et al., 2002) and may be greatly influenced by preferential flow (Fuchs et al., 2009; Zhang et al., 2011).

The role of natural levees is likely different in fine-grained floodplains such as the Atchafalaya River basin than in coarser-grained floodplains described in much of the floodplain literature (e.g., Jones et al., 2008; Lewandowski et al., 2009). In low-gradient floodplains, natural levees are often the highest elevation areas on the landscape and delineate 
surface drainages, but particularly in fine-grained systems, they may also be the most permeable features on the landscape (Tye and Coleman, 1989). High conductivity features in fine-grained systems can have a large effect on water and solute transport (Haria et al., 1994), and layering of low and high conductivity soils likely compounds this effect (Nield, 2008), but few studies have focused on hydrologic cycling in floodplains in general and fine-grained floodplains in particular.

In this study we focus on a scale intermediate between a soil core and a catchment, which we consider a mesoscale. A primary difficulty in quantifying subsurface exchange is determining the appropriate scale of measurement, because rates of water and solute transport in field soils often vary spatially by orders of magnitude. Preferential flow paths are widely recognized mechanisms of spatially varying transport rates (Flury et al., 1994; Sidle et al., 2001; Legout et al., 2009) and have been observed in wetland sediments (Harvey et al., 1995; Noguchi et al., 1999). Several authors have noted that hydrologic characteristics vary with scale (e.g., Seyfried and Wilcox, 1995; Kabat et al., 1997; Kirchner, 2006), and because preferential flow tends to be dominated by a few, high-conductivity features, its effect on water and solute transport likely varies with scale; yet hydraulic conductivity is commonly measured at a soil core or bore hole scale (e.g., Bradley, 2002). If preferential flow is the dominant pathway, characterizing connectivity via subsurface exchange requires analyzing spatial variability of transport mechanisms at a scale large enough to encompass fieldscale heterogeneity but small enough to be relevant to lateral exchange through natural levees.

In hydrology there is no broadly accepted definition of connectivity (Bracken and Croke, 2007), so methods of measurement vary considerably. In unsaturated environments, soil moisture is a useful metric, because connectivity is thought to occur in discrete paths of saturation within the vadose zone (Tromp-van Meerveld and McDonnell, 2006), but in wetland environments where saturation is more prevalent, hydrological connectivity may be generally defined by either hydraulic or chemical transport. Hydraulic methods rely on measurements of hydraulic response to an imposed gradient, a measure of pressure propagation that does not necessarily translate into groundwater flow velocity (McDonnell et al., 2007; Lewandowski et al., 2009). Chemical transport, which is essential to understanding exchange of nutrients, dissolved organic matter, and other solutes, is commonly measured with tracer tests. Pressure propagation in a subsurface matrix occurs faster than individual molecules can travel, so hydraulic methods tend to yield higher estimates of subsurface transport rates compared to tracer tests (e.g., Elci and Molz, 2009). Therefore, the definition of connectivity determines the appropriate metric.

Here we define connectivity as the rate of water and solute exchange between wetlands and river channels, and we are specifically interested in identifying the driving mechanisms of exchange. We hypothesize that, in the absence of surface connectivity, exchange is largely a function of preferential lateral subsurface flow through natural levees. To test this, we modeled residence time distributions of both pressure (hydraulic connectivity) and tracer (chemical connectivity) in an array of shallow monitoring wells in a natural levee and derived effective hydraulic conductivity $(K)$ values. We obtained data by creating an artificial hydraulic gradient across a natural levee and measuring spatially variable subsurface water levels and tracers. We modeled residence times of pressure and tracer according to linear systems theory (Dooge, 1973) by parameterizing simple models to fit experimental data.

\subsection{Residence time modeling of subsurface flow: theory}

Conceptually, an individual molecule of solute traveling in the subsurface may take one of many possible flow paths; the time a molecule spends traveling along an individual flow path is its residence time, and the set of residence times for all flow paths between two points makes up a residence time distribution (RTD) (McGuire et al., 2002). For a conservative tracer, the change in solute concentration of water through time, the breakthrough curve, is a function of the RTD. The mean residence time (MRT) is the mean linear velocity of the groundwater and provides a useful first-order description of the distribution; however, other moments and central tendency measures may also contain important information (McGuire and McDonnell, 2006).

When a groundwater system is hydraulically perturbed by an input of water, the pressure head increases at the origin of the perturbation, and the resulting pressure wave is transmitted through the system at a velocity that is a function of hydraulic gradient and conductivity (e.g., Beven, 1981). Pressure transport may be many orders of magnitude faster than tracer transport (Rasmussen et al., 2000). The RTD of the pressure wave describes the movement of energy - as opposed to the RTD of tracer, which describes the movement of mass - and is useful for interpreting transport times and flow mechanisms of total water volume in the system.

In a field situation where direct measurement of subsurface flow is difficult, analyzing the shape of a breakthrough curve is a practical method to estimate the RTD of soil water (Chazarenc et al., 2003). A linear additive model, in which inputs to a system are related to responses by a transfer function, is a common approach (Jury, 1982; Asano et al., 2002). In this application, the transfer function is the RTD of the soil water. In a solute transport application under a spatially uniform flow rate, the probability $P$ that a tracer will travel distance $L$ after a given amount of time $t$ has elapsed is

$P_{L}(t)=\int_{0}^{t} g_{L}\left(t^{\prime}\right) \mathrm{d} t^{\prime}$, 
where $g_{L}\left(t^{\prime}\right)$ is the transfer function (Jury, 1982) and $t^{\prime}$ indicates a shift backward in time from $t$. Hydrologic systems are often defined in terms of flow, because it is a convenient independent variable for tracer transport (Jury et al., 1986). To model this, Eq. (1) can be generalized for any domain $I$ such as time, flow or some other less physical domain. In a simple linear system (Dooge, 1973), convolving input $x(I)$ with $g$ yields overall response $y(I)$ as a superposition of the individual responses to all units of input:

$$
y(I)=\int_{0}^{I} x\left(I-I^{\prime}\right) g\left(I^{\prime}\right) \mathrm{d} I^{\prime} .
$$

In field applications, measurements are made at discrete intervals, so that Eq. (2) becomes a summation:

$$
y(I)=\sum_{I^{\prime}=1}^{I} x\left(I-I^{\prime}\right) g\left(I^{\prime}\right) .
$$

\section{Methods}

\subsection{Field site and experiments}

We established an approximately $390-\mathrm{m}^{2}$ study site (Fig. 1) on a forested natural levee of a small stream in the Atchafalaya River basin, a large riverine wetland in Louisiana, USA $\left(30^{\circ} 5^{\prime} 18^{\prime \prime} \mathrm{N}, 91^{\circ} 35^{\prime} 58^{\prime \prime} \mathrm{W}\right)$. In the past century, anthropogenic alterations have increased Mississippi River flow to the Atchafalaya River basin, altering sedimentation patterns and geomorphology (Fisk, 1952; Aslan et al., 2005). The study site is in an area of rapid sediment deposition ( $\sim 14 \mathrm{~mm} \mathrm{yr}^{-1}$ ) (Hupp, 2000; Hupp et al., 2008) on a former deltaic lake bottom (Tye and Coleman, 1989; Aslan et al., 2005). Because of high levees on the Atchafalaya River, there is limited surface hydrologic connectivity between the study area and the larger riverine system except at unusually high water. Textural analysis of natural levee soils indicated a thin upper layer of silt loam underlain by alternating layers of silty clay and silty clay loam (Fig. 2). A clay layer beginning at approximately $2 \mathrm{~m}$ coincides with the probable elevation of the former lake bottom. Soluble salts for the upper $2 \mathrm{~m}$ were between 0.13 and $0.5 \mathrm{ppt}$ but were up to $2.92 \mathrm{ppt}$ at greater depths (Fig. 3). Sulfate salts that commonly form in base-rich backswamp soils of the Atchafalaya River basin (Barron, 1996) may be responsible for the high salinity at depth. Additionally, the soils contain a large, unquantified, and spatially variable component of organic matter and a root depth of at least $2 \mathrm{~m}$.

Naturally occurring hydraulic gradients across the experimental natural levee are typically small and transient, making chemical and hydraulic fluxes difficult to measure. Therefore, to obtain data useful for modeling properties of the natural levee, we created a controlled hydraulic condition by

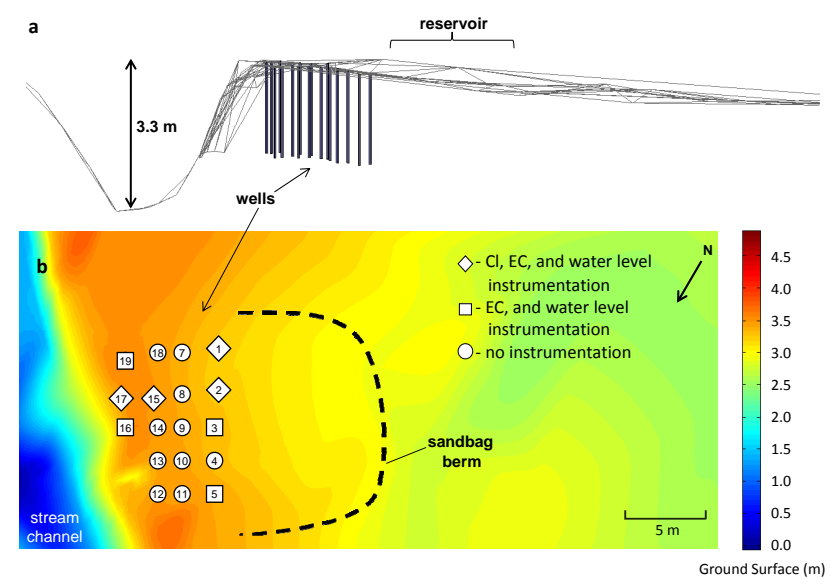

Fig. 1. Side view (a) and plan view (b) of site topography (meters above datum) and well layout.

constructing a semicircular berm using sandbags and plastic sheeting to create a $300-\mathrm{m}^{2}$ reservoir on the swampward slope of the natural levee (Fig. 1). In a pair of experiments, we pumped water into the reservoir to create a controlled hydraulic gradient large enough to generate flow through the levee and enable modeling of the subsurface properties. The reservoir allowed control of hydraulic head and chemical composition of the input water but did not conserve mass of tracer or water, because downgradient subsurface flow paths were in all directions from the reservoir, not just through the levee.

A $10 \mathrm{~m} \times 9 \mathrm{~m}$ grid of monitoring wells on the levee crest installed to a depth of $2 \mathrm{~m}$ allowed measurement of spatially variable hydraulic head and hydrochemistry (Figs. 1 and 2). Wells were installed by drilling to the clay layer, which was approximately $2 \mathrm{~m}$ deep, using a 6.4-cm-diameter hand auger and were screened along the full depth with slotted PVC pipe. We used PVC wells capped at the bottom and two types of well screens, which served the same function. One type was slotted horizontally along its entire length with a table saw and wrapped in nylon stockings; the other type of well was perforated along its entire length with $0.015 \mathrm{~cm}$ slots (Atlantic Screen, Inc.). Voids around the wells were filled with sand for all but the upper $15 \mathrm{~cm}$, and bentonite clay pellets filled the void for the remaining depth to prevent surface water infiltration along the outside of the well casings. Wells were developed through several reservoir-filling events prior to the experiments.

Instrumentation of the monitoring wells included four wells with ion-specific electrodes (ISEs) (TempHion 2, Instrumentation Northwest, Inc.) to measure chloride concentration with a $\pm 0.4 \%$ accuracy, electrical conductivity (EC)/temperature sensors (CS547A, Campbell Scientific, Inc.) with $\pm 5 \%$ accuracy, and capacitance water level recorders (Dataflow Systems PTY LTD) with $\pm 5 \mathrm{~mm}$ accuracy. Three additional wells contained only an EC/temperature sensor and a water level recorder. All sensors 


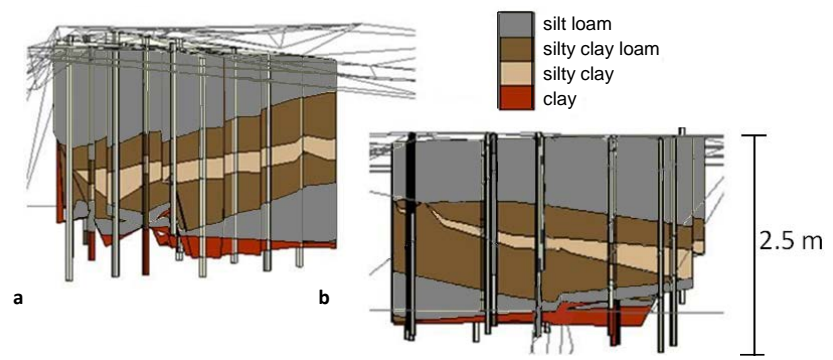

Fig. 2. (a) Soil stratigraphy interpolated from soil texture analysis, view from the side and (b) looking swampward from levee.

were programmed to take readings at 3-min intervals, and the EC and ISE sensors were linked to a central datalogger (CR1000, Campbell Scientific, Inc.).

We conducted two tracer tests - a passive tracer test on 28 January 2009 and an active tracer test on 2 February 2009 - by pumping water into the reservoir and monitoring hydraulic and chemical responses in the wells (Table 1). In the passive tracer test (hereafter referred to as the no-salt test), we filled the reservoir with unadulterated water from the channel; in the active tracer test (hereafter referred to as the salt-added test), we added potassium chloride to the reservoir water. The natural electrical conductivity (EC) of the bayou water was an order of magnitude lower than the EC of soil pore water owing to high base saturation in the young sediments, so bayou water was useful as a natural tracer of event water in the pumping experiments. Both active and passive tracers were conservative, and we expected them to measure the same process in the same way and thus to behave similarly under similar conditions.

For all tests, we pumped water from the nearby stream channel into an elevated holding tank adjacent to the well field, from which water flowed via gravity through a pipe into the reservoir. For the salt-added test, we added $\mathrm{KCl}$ to the tanks and maintained a constant concentration during pumping by mixing salt in the holding tank and monitoring EC of the outflow using a hand-held EC meter. The tracer water was maintained at an EC of $6 \mathrm{mS} \mathrm{cm}^{-1}$, which is $\sim 6$ times greater than soil water. A water level recorder and EC sensor were also installed in the reservoir.

Hydraulic conditions varied considerably between the two tests. In the no-salt test, the water table was near the soil surface and the stream was within a few centimeters of bankfull, so ponding in the reservoir began almost immediately. In contrast, the salt-added test occurred when the water table was lower, and water absorption by the dry soil delayed establishment of a hydraulic gradient. Because stream stage was higher during the no-salt test, the hydraulic gradient achieved was less than for the salt-added test when stage was lower (Table 1), although the maximum depth of water in the reservoir was the same for both tests: $12 \mathrm{~cm}$. Additionally, pumping rate differed between the two tests as a result of a brief cessation of pumping during the salt-added test.

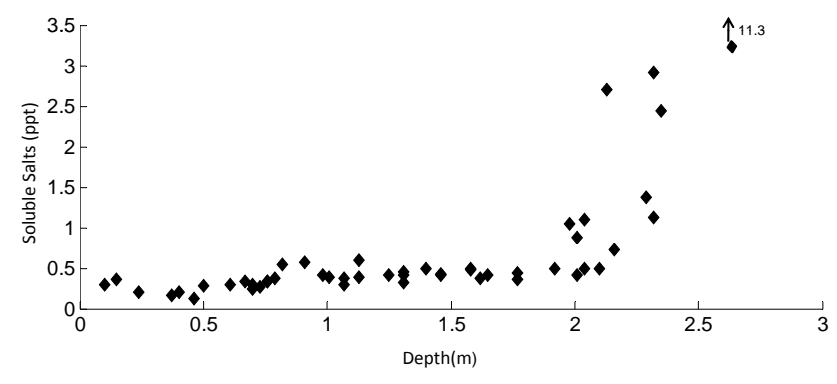

Fig. 3. Soluble salts for soil samples collected during well excavation.

\subsection{Modeling}

We used a linear additive model to parameterize the transfer functions $(g)$ of pressure and tracer. For tracers, modeled quantities were electrical conductivity and chloride concentration (chemographs); for pressure, the modeled quantity was hydraulic head (hydrographs). For each modeled hydrograph and chemograph, we fit common transfer functions to the experimental data using a Nelder-Mead numerical optimization search (Lagarias et al., 1998) within Matlab to obtain the parameter set that maximized the NashSutcliffe (1970) efficiency $(\varepsilon)$. We investigated two common statistical distributions as transfer functions: the exponential distribution,

$g(t)=a e^{-a t}$,

where $a$ is a parameter, and the mean of the distribution is $a^{-1}$; and the gamma distribution,

$g(t)=\frac{t^{b-1} \cdot e^{-a t}}{a^{-1} b \Gamma(b)}$,

where $a$ and $b$ are parameters, $\Gamma$ ( ) is the gamma function, and the mean of the distribution is $b a^{-1}$.

Theoretically, the exponential distribution describes a collection of individual flow paths of varying lengths from zero to infinity that do not intersect, and the gamma distribution is an infinite series of exponentials. The exponential distribution assumes that the outflow is linearly related to the average or well-mixed behavior of the system (Duffy and Gelhar, 1985) and is often used to model solute transport in hydrologic systems (Maloszewski and Zuber, 1998; McGuire and McDonnell, 2006). However, gamma-distributed transfer functions, having an additional parameter, provide a better fit to time-series hydrological data and are commonly used for analysis (e.g., Soulsby et al., 2011; Verma et al., 2011). To account for time delays between the hydraulic rise in the reservoir (and concurrent chemical input) and the well response, we added a parameter $(d)$ to each distribution that shifted the transfer function in time (or head differential time). We optimized the delay as an additional parameter for each model fit, and the transfer function was defined as $g(t+d)$. 
Table 1. Summary of pumping events.

\begin{tabular}{|c|c|c|c|c|c|c|}
\hline \multirow[b]{2}{*}{ Test } & \multicolumn{2}{|c|}{ Pre-Event Water } & \multicolumn{2}{|c|}{ Event Water } & \multirow{2}{*}{$\begin{array}{l}\text { Mean } \\
\text { Hydraulic Head } \\
\text { Differential (m) }\end{array}$} & \multirow{2}{*}{$\begin{array}{l}\text { Duration of } \\
\text { Imposed } \\
\text { Gradient (h) }\end{array}$} \\
\hline & $\begin{array}{c}\mathrm{EC} \\
\left(\mathrm{mS} \mathrm{cm}^{-1}\right)\end{array}$ & $\begin{array}{c}\mathrm{Cl}^{-} \\
\left(\mathrm{mg} \mathrm{L}^{-1}\right)\end{array}$ & $\begin{array}{l}\mathrm{EC} \\
\left(\mathrm{mS} \mathrm{cm}{ }^{-1}\right)\end{array}$ & $\begin{array}{l}\mathrm{Cl}^{-} \\
\left(\mathrm{mg} \mathrm{L}^{-1}\right)\end{array}$ & & \\
\hline No-salt & $1-2.5$ & $50-300$ & 0.3 & 55 & 0.12 & 6.5 \\
\hline Salt-added & $1-2.5$ & $50-300$ & 6 & 1000 & 0.70 & 5 \\
\hline
\end{tabular}

Precipitation, wind and lunar tides, and diurnal evapotranspiration patterns caused perpetual fluctuations in the stream channel and shallow groundwater, so a small hydraulic gradient always existed across the levee. Modeling the hydraulic responses in each well to forcing events required separating the imposed hydraulic differentials from the baseline rising or receding behavior of the water table. We estimated the hydraulic head above baseline using baseflow hydrograph separation, which is commonly used to characterize streamflow response to precipitation (Hewlett, 1982). To determine the hydraulic baseline, we visually fitted a curve for each well and each event to approximate the behavior of the water table as it would have likely been in the absence of perturbation (e.g., Fig. 4). We used the point of departure from and return to the hydraulic baseline to define hydraulic response in a specific well. Input was defined as the water level in the reservoir above an arbitrary datum regardless of initial water table elevation, which varied among wells.

As with hydraulic modeling, temporal fluctuations in natural chemistry meant that modeling chemical response to each forcing event required defining a baseline for each chemograph. We defined water chemistry changes as the ratio of new water to old water, following concepts of storm runoff generation (Church, 1997; Jones et al., 2006) that new water has the chemical signature of event water, and old water has the chemical signature of the pre-existing subsurface soil water, which emerges through displacement by new water entering the soil. We assumed new water entered the soil either from the reservoir or from recent rainfall or bank overflow events and defined it as the concentration of tracer in the reservoir water for each experiment. Old water was defined according to the maximum concentrations of tracer measured in native groundwater across the well field for the period of record (EC $2.5 \mathrm{mS} \mathrm{cm}^{-1}$; chloride $300 \mathrm{mg} \mathrm{L}^{-1}$ ). In the saltadded test, distinguishing old water from diluted reservoir water would have required an additional independent tracer; therefore, we defined the old water component of the saltadded test as the local antecedent tracer concentration at each well.

Tracer moves through a system as a function of total flow, so for tracer modeling, the domain $(I)$ in Eq. (3) would have ideally been flow. Our experimental design, however, did not conserve mass of water or tracer because input water flowed in all directions in the subsurface, so we used the hydraulic head differential between the reservoir and the stream

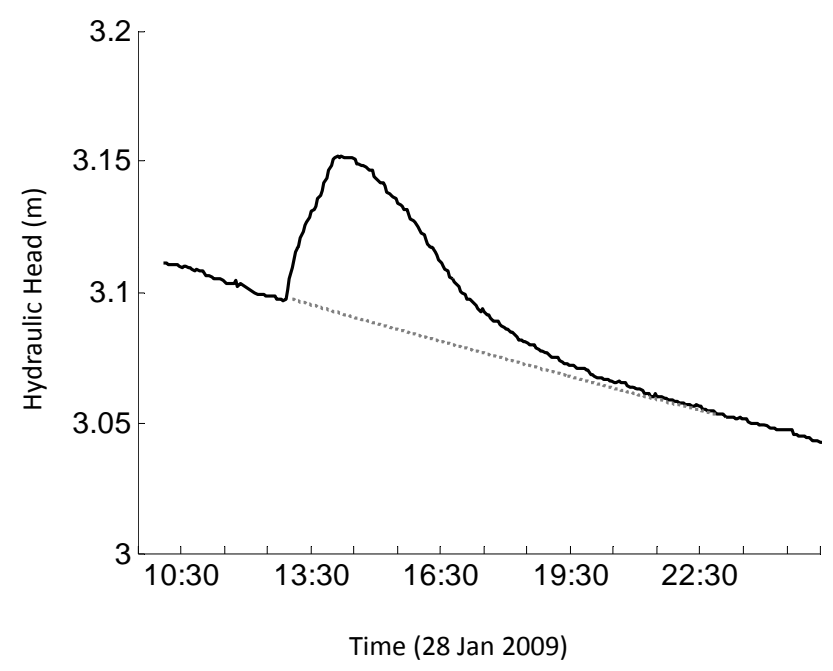

Fig. 4. An example hydraulic baseline (dotted line) approximated well response (solid line) in the absence of perturbation (well 3, no-salt test).

channel as a surrogate for flow. We then modeled chemical response as the proportion of new water as a function of the cumulative product of time and hydraulic head differential between the reservoir and stream channel. Thus, I for chemograph modeling was "head differential time," which is the time vector weighted by the rate of accumulated hydraulic head differential. Head differential time was limited to the duration of imposed hydraulic gradient, so breakthrough curves and fitted transfer functions were truncated at the maximum head differential. Breakthrough curves for pressure transport were not truncated, because they were modeled in the time domain.

We calculated effective hydraulic conductivity $(K)$ from best-fit MRTs of tracer residence time distributions at each well using Darcy's law $q=K \frac{\Delta h}{l}$, where $q=\frac{l}{\text { MRT }}, l$ is estimated pathlength, and $\Delta h$ is the mean head differential between the reservoir and the stream channel for each experiment. Accordingly,

$K=\frac{l^{2}}{\mathrm{MRT} \cdot \Delta h}$.

In head differential time, MRTs were in units of $\mathrm{m} \cdot \mathrm{min}$ (head differential - time); dividing by the mean head differential during each experiment $(0.12 \mathrm{~m}$ for the no-salt test and 

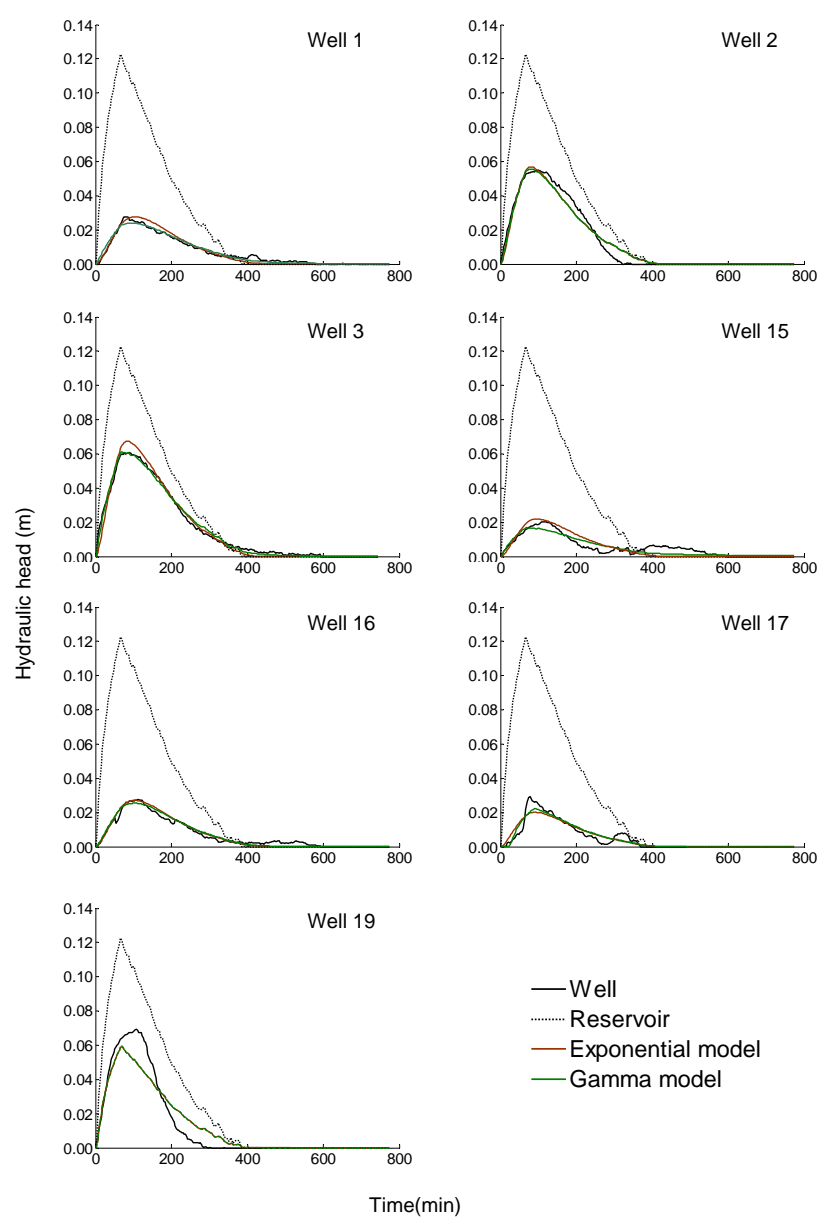

Fig. 5. Optimized models of pressure transport for no-salt test.

$0.7 \mathrm{~m}$ for the salt-added test) yielded MRT estimates in units of time. We estimated path lengths as the horizontal, straightline distance from the approximate areal center of the reservoir to each well, assuming that the effects of both tortuosity of flow paths and temporal variability of the location of the reservoir edge closest to monitoring wells were negligible. In reality, these assumptions were probably not met exactly, and this is discussed in Sect. 4.1.

\section{Results}

Linear system models accurately simulated both pressure transport (grand mean $\varepsilon=0.93$ ) (Tables 2-3, Figs. 5-6) and tracer transport (grand mean $\epsilon=0.64$ ) (Tables 4-5, Figs. 7$9)$. As expected, pressure increases from hydraulic perturbation propagated rapidly. The time delays between when water entered the reservoir and pressure increased in the wells were less than the 3-min logging interval in all cases. Mean residence times for pressure transport were between 1-43 min for the best-fit models in the no-salt test and between 40$145 \mathrm{~min}$ for the best-fit model in the salt-added test.
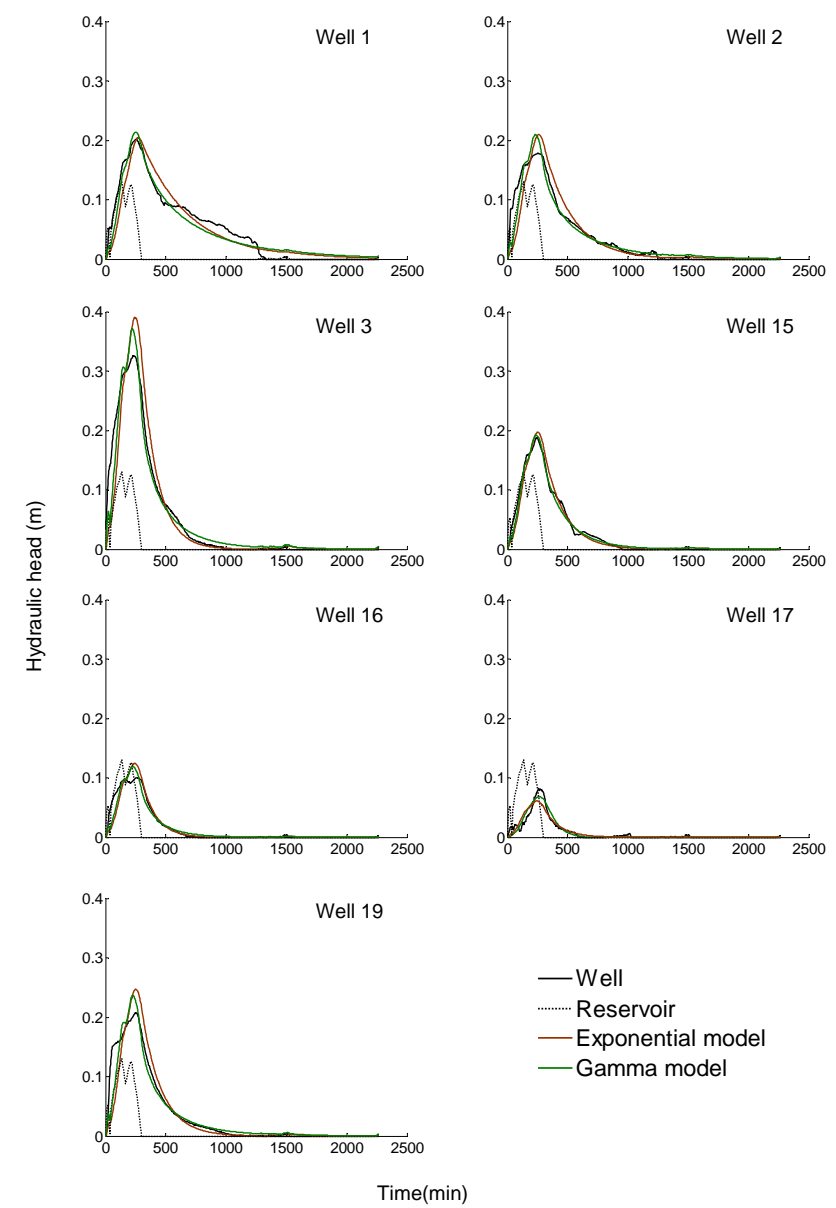

Fig. 6. Optimized models of pressure transport for salt-added test.

By comparison, tracer transport was generally slower and more spatially variable. The time delays between water entering the reservoir and chemical responses in the wells varied between 21-636 min for the best-fit models in the nosalt test and between 4-160 min for the best-fit models in the salt-added test. Mean residence times were much longer: between $2.2 \times 10^{3}$ and $2.0 \times 10^{6} \mathrm{~min}$ for the best-fit models in the no-salt test, and between $1.5 \times 10^{2}$ and $1.0 \times 10^{6}$ for the best-fit models in the salt-added test. The orders-ofmagnitude difference between the time until arrival of tracer and the MRT is a reflection of long residence times in the tails of the optimized distributions. Effective hydraulic conductivity estimates derived from the best-fit modeled tracer transport rates were between $1.4 \times 10$ and $1.1 \times 10^{3} \mathrm{md}^{-1}$ for the no-salt and between $2.4 \times 10^{-1}$ and $1.7 \times 10^{3} \mathrm{~m} \mathrm{~d}^{-1}$ for the salt-added tests.

Spatial variability of tracer transport was greater during the salt-added test than during the no-salt test. The mass difference between the integral of the input and response functions, expressed as a proportional change in new or old water, provided a measure of tracer mass recovery that was useful for comparing spatial variability of transport (Fig. 10). In 
Table 2. Modeling results of pressure transport for no-salt test. The best-fit value for the time delay parameter $d$ was zero for all tests. Negative values of Mass Diff (proportional mass difference) indicate an over-prediction of mass in the tails of residence time distributions.

\begin{tabular}{|c|c|c|c|c|c|c|c|c|c|}
\hline \multirow[b]{2}{*}{ Model } & \multirow[b]{2}{*}{ Well } & \multirow{2}{*}{$\begin{array}{r}\text { Pathlength } \\
(\mathrm{m})\end{array}$} & \multirow{2}{*}{$\begin{array}{l}\text { Efficiency } \\
\quad(\varepsilon)\end{array}$} & \multirow[b]{2}{*}{ Mass Diff } & \multicolumn{2}{|c|}{ Parameter } & \multirow{2}{*}{$\begin{array}{l}\text { MRT } \\
(\min )\end{array}$} & \multirow{2}{*}{$\begin{array}{l}\text { Variance } \\
\left(\min ^{2}\right)\end{array}$} & \multirow{2}{*}{$\begin{array}{l}\text { Velocity } \\
\left(\mathrm{ms}^{-1}\right)\end{array}$} \\
\hline & & & & & $a$ & $b$ & & & \\
\hline \multirow[t]{8}{*}{ Exp } & 1 & 9.1 & 0.96 & $5.6 \times 10^{-8}$ & 0.0312 & - & 32 & $1.0 \times 10^{3}$ & $4.7 \times 10^{-3}$ \\
\hline & 2 & 13.9 & 0.98 & $2.7 \times 10^{-15}$ & 0.0721 & - & 14 & $1.9 \times 10^{2}$ & $1.7 \times 10^{-2}$ \\
\hline & 3 & 17.1 & 0.98 & $1.2 \times 10^{-12}$ & 0.0603 & - & 17 & $2.8 \times 10^{2}$ & $1.7 \times 10^{-2}$ \\
\hline & 15 & 10.9 & 0.71 & $1.3 \times 10^{-9}$ & 0.0396 & - & 25 & $6.4 \times 10^{2}$ & $7.2 \times 10^{-3}$ \\
\hline & 16 & 8.2 & 0.96 & $2.9 \times 10^{-8}$ & 0.0325 & - & 31 & $9.5 \times 10^{2}$ & $4.5 \times 10^{-3}$ \\
\hline & 17 & 11.6 & 0.89 & $6.3 \times 10^{-11}$ & 0.0467 & - & 21 & $4.6 \times 10^{2}$ & $9.0 \times 10^{-3}$ \\
\hline & 19 & 15.5 & 0.91 & $9.9 \times 10^{-2}$ & 0.2755 & - & 4 & $1.3 \times 10^{1}$ & $7.1 \times 10^{-2}$ \\
\hline & & Mean & 0.91 & $1.2 \times 10^{-8}$ & & & 21 & $5.1 \times 10^{2}$ & $1.8 \times 10^{-2}$ \\
\hline \multirow[t]{8}{*}{ Gamma } & 1 & 9.1 & 0.98 & $2.0 \times 10^{-3}$ & 0.0198 & 0.3206 & 16 & $8.2 \times 10^{2}$ & $9.3 \times 10^{-3}$ \\
\hline & 2 & 13.9 & 0.98 & $-1.3 \times 10^{-6}$ & 0.1222 & 0.5646 & 5 & $3.8 \times 10^{1}$ & $5.0 \times 10^{-2}$ \\
\hline & 3 & 17.1 & 0.99 & $9.3 \times 10^{-4}$ & 0.0217 & 0.1833 & 8 & $3.9 \times 10^{2}$ & $3.4 \times 10^{-2}$ \\
\hline & 15 & 10.9 & 0.82 & $5.8 \times 10^{-2}$ & 0.0036 & 0.1541 & 43 & $1.2 \times 10^{4}$ & $4.2 \times 10^{-3}$ \\
\hline & 16 & 8.2 & 0.96 & $1.1 \times 10^{-5}$ & 0.0515 & 0.5804 & 11 & $3.2 \times 10^{2}$ & $1.2 \times 10^{-2}$ \\
\hline & 17 & 11.6 & 0.92 & $7.7 \times 10^{-15}$ & 2.8604 & 24.86 & 9 & $3.0 \times 10^{0}$ & $2.2 \times 10^{-2}$ \\
\hline & 19 & 15.5 & 0.91 & $-9.9 \times 10^{-7}$ & 3.6603 & 5.068 & 1 & $0.38 \times 10^{-1}$ & $1.9 \times 10^{-1}$ \\
\hline & & Mean & 0.94 & $8.7 \times 10^{-3}$ & & & 13 & $1.9 \times 10^{3}$ & $4.5 \times 10^{-2}$ \\
\hline
\end{tabular}

Table 3. Modeling results of pressure transport for salt-added test. The best-fit value for the time delay parameter $d$ was zero for all tests. Negative values of Mass Diff (proportional mass difference) indicate an over-prediction of mass in the tails of residence time distributions.

\begin{tabular}{|c|c|c|c|c|c|c|c|c|c|}
\hline \multirow[b]{2}{*}{ Model } & \multirow[b]{2}{*}{ Well } & \multirow{2}{*}{$\begin{array}{r}\text { Pathlength } \\
\text { (m) }\end{array}$} & \multirow{2}{*}{$\begin{array}{c}\text { Efficiency } \\
(\varepsilon)\end{array}$} & \multirow[b]{2}{*}{ Mass Diff } & \multicolumn{2}{|c|}{ Parameter } & \multirow{2}{*}{$\begin{array}{l}\text { MRT } \\
(\min )\end{array}$} & \multirow{2}{*}{$\begin{array}{c}\text { Variance } \\
\left(\min ^{2}\right)\end{array}$} & \multirow{2}{*}{$\begin{array}{l}\text { Velocity } \\
\left(\mathrm{ms}^{-1}\right)\end{array}$} \\
\hline & & & & & $a$ & $b$ & & & \\
\hline \multirow[t]{8}{*}{ Exp } & 1 & 9.1 & 0.91 & $9.8 \times 10^{-3}$ & 0.0025 & - & 400 & $1.6 \times 10^{5}$ & $3.8 \times 10^{-4}$ \\
\hline & 2 & 13.9 & 0.88 & $2.0 \times 10^{-3}$ & 0.0043 & - & 233 & $5.4 \times 10^{4}$ & $9.9 \times 10^{-4}$ \\
\hline & 3 & 17.1 & 0.91 & $3.2 \times 10^{-3}$ & 0.0075 & - & 133 & $1.8 \times 10^{4}$ & $2.1 \times 10^{-3}$ \\
\hline & 15 & 10.9 & 0.98 & $3.1 \times 10^{-3}$ & 0.0060 & - & 167 & $2.8 \times 10^{4}$ & $1.1 \times 10^{-3}$ \\
\hline & 16 & 8.2 & 0.92 & $3.0 \times 10^{-3}$ & 0.0085 & - & 118 & $1.4 \times 10^{4}$ & $1.2 \times 10^{-3}$ \\
\hline & 17 & 11.6 & 0.90 & $3.0 \times 10^{-3}$ & 0.0075 & - & 133 & $1.8 \times 10^{4}$ & $1.4 \times 10^{-3}$ \\
\hline & 19 & 15.5 & 0.88 & $2.9 \times 10^{-3}$ & 0.0061 & - & 164 & $2.6 \times 10^{4}$ & $1.6 \times 10^{-3}$ \\
\hline & & Mean & 0.91 & $4.1 \times 10^{-3}$ & & & 192 & $1.5 \times 10^{4}$ & $1.3 \times 10^{-3}$ \\
\hline \multirow[t]{8}{*}{ Gamma } & 1 & 9.1 & 0.95 & $2.0 \times 10^{-2}$ & 0.0050 & 0.7273 & 145 & $2.9 \times 10^{4}$ & $1.0 \times 10^{-3}$ \\
\hline & 2 & 13.9 & 0.94 & $7.7 \times 10^{-3}$ & 0.0062 & 0.5784 & 93 & $1.5 \times 10^{4}$ & $2.5 \times 10^{-3}$ \\
\hline & 3 & 17.1 & 0.97 & $3.2 \times 10^{-3}$ & 0.0089 & 0.4827 & 54 & $6.0 \times 10^{3}$ & $5.3 \times 10^{-3}$ \\
\hline & 15 & 10.9 & 0.99 & $3.2 \times 10^{-3}$ & 0.0126 & 0.7466 & 59 & $4.7 \times 10^{3}$ & $3.1 \times 10^{-3}$ \\
\hline & 16 & 8.2 & 0.94 & $2.7 \times 10^{-3}$ & 0.0135 & 0.5918 & 44 & $3.2 \times 10^{3}$ & $3.1 \times 10^{-3}$ \\
\hline & 17 & 11.6 & 0.92 & $5.3 \times 10^{-4}$ & 0.0524 & 2.1147 & 40 & $8.1 \times 10^{2}$ & $4.7 \times 10^{-3}$ \\
\hline & 19 & 15.5 & 0.93 & $8.4 \times 10^{-3}$ & 0.0079 & 0.5249 & 66 & $8.4 \times 10^{3}$ & $3.9 \times 10^{-3}$ \\
\hline & & Mean & 0.95 & $6.6 \times 10^{-3}$ & & & 72 & $9.6 \times 10^{3}$ & $3.4 \times 10^{-3}$ \\
\hline
\end{tabular}

the no-salt test, the proportion of the total recovered tracer mass was distributed approximately evenly among wells (response in wells 15 and 17 was excluded, because tracer transport was not modeled, and proportional change was not measurable). In the salt-added test however, spatially disparate proportional changes in soil water chemistry were apparent.
Chloride increased in response to pumping in all four wells where we measured it, but EC responses varied: it increased in two wells (15 and 17) and decreased or fluctuated in the remaining wells ( 2 and 1 , respectively). Despite the inherent collinearity of the two tracers, in well 2 , the direction of the chloride response (increase) was opposite the EC response 


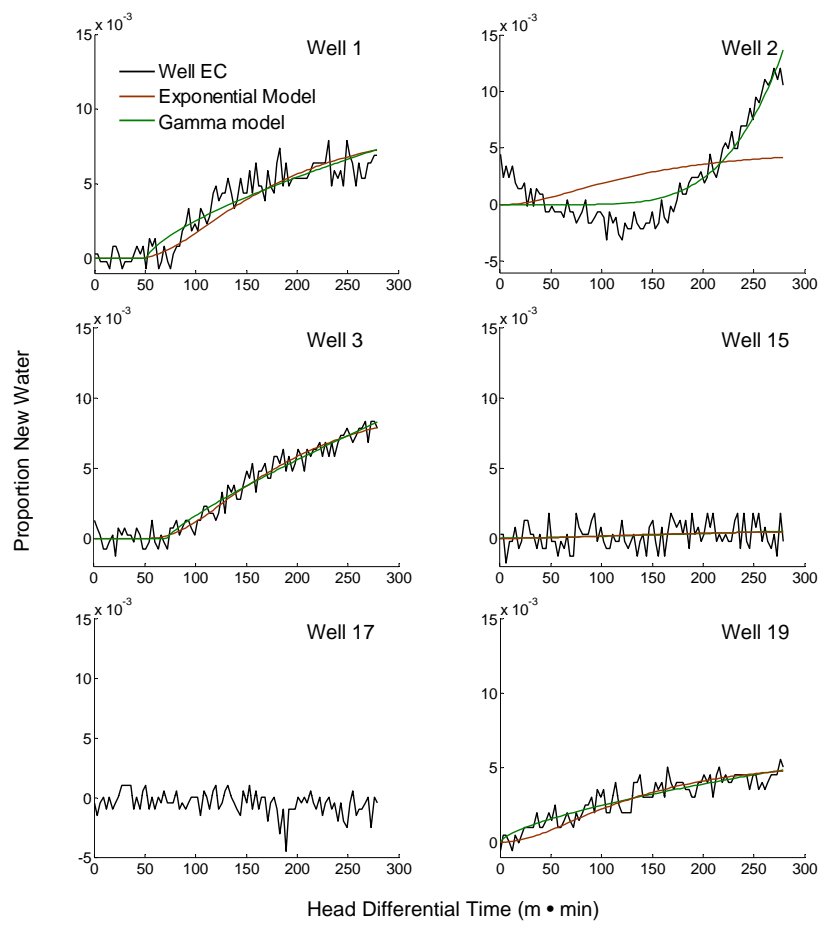

Fig. 7. Optimized models of EC truncated at the end of head differential time for no-salt test. EC response in well 17 was not modeled.

(decrease) (Fig. 9), so in this case, the calculation reflects a proportional change in old-water EC rather than directly recovered tracer mass.

Although the RTDs for tracer and pressure transport were similar in some respects, the differences were considerable. Pressure transport differed from tracer transport in both mean velocity and temporal variability. The mean velocity of pressure transport was faster than the mean velocity of tracer transport by two orders of magnitude $\left(1.7 \times 10^{-2}\right.$ and $4.6 \times 10^{-4} \mathrm{~m} \mathrm{~s}^{-1}$, respectively), and the mean variance of pressure RTDs was smaller than the mean variance of tracer RTDs by seven orders of magnitude $\left(1.4 \times 10^{4} \mathrm{~min}^{2}\right.$ and $7.9 \times 10^{11} \mathrm{~min}^{2}$, respectively) (Tables $2-5$ ). For both tracer and pressure transport, the gamma distribution provided the best models, which is expected, because it has an additional fitting parameter. The majority of optimized gamma RTDs for both measures of transport had a modal residence time probability at $t=0$, indicating rapid response to input and approximating the exponential distribution (when $b=1$, the gamma distribution is exponential).

There were some wells in which water chemistry differed from our simple conceptual model that input would cause a shift toward either old or new water chemistry. For example, in the no-salt test, EC in well 17 spiked in the direction of old water but subsequently returned to pre-event EC during the period of imposed hydraulic gradient (Fig. 7). Similarly, in the salt-added test, wells 1 and 3 displayed more complex chemical behavior than could be described by our
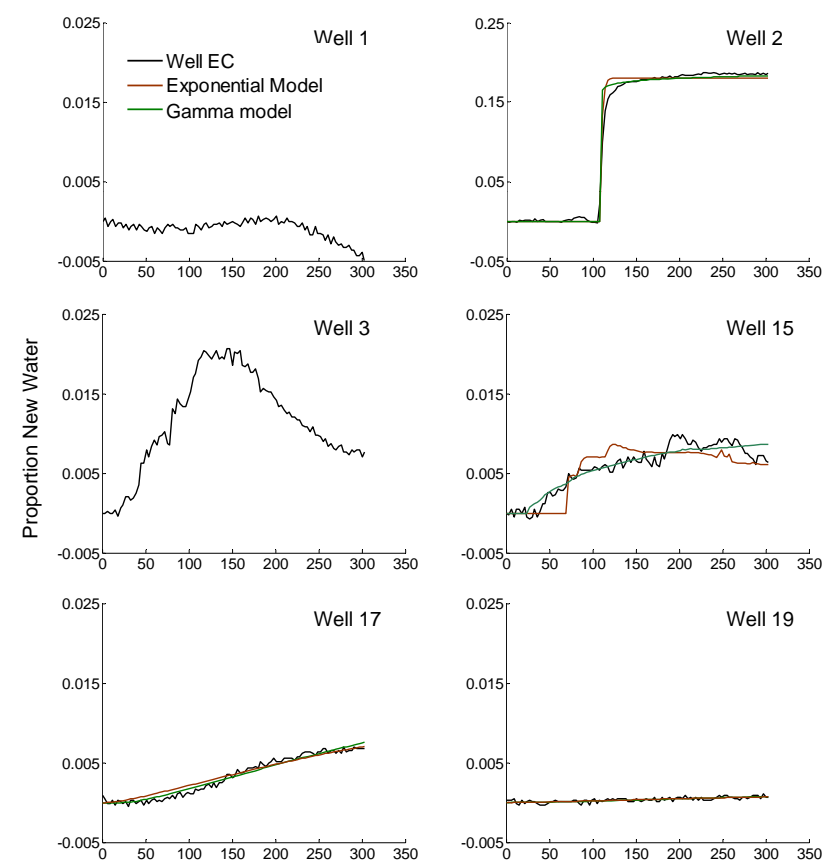

Head Differential Time $(\mathrm{m} \cdot \mathrm{min})$

Fig. 8. Optimized models of EC truncated at the end of head differential time for salt-added test. EC response in wells 1 and 3 was not modeled. Well 2, which was modeled with an inverse input function, is displayed on a larger-scale axis because of larger-scale response.

simple model (Fig. 8). In these cases, the linear system model was not appropriate, and we did not model tracer response. These nonbehavioral cases included all measured chloride responses in the no-salt test (not shown) as well as the abovementioned cases with multiple inflection points. For those that were modeled, the proportional mass difference between the integral of the response curve and the integral of the simulation reflected discrepancies in curve shape and provided an additional measure of model fit (Tables 4-5), but values may also reflect mass loss from numerical integration, because the mass under the response curve was calculated by summing the change during the logging interval, but the simulation curve was continuous.

\section{Discussion}

\subsection{Interpreting tracers}

We designed this field experiment to find the degree to which preferential flow is important to connectivity through a natural levee, and we used a simple modeling technique to roughly quantify this. Despite numerous unknowns and potential nonlinearities of flow response, the linear system model structure allowed estimates of pressure and tracer transport at the mesoscale. The benefit of using a linear system approach is that it does not require deterministic 
Table 4. Modeling results of tracer transport for no-salt test. Negative values of Mass Diff (proportional mass difference) indicate greater mass in the model than in the observations. Dashes indicate parameters that were not modeled for a specific well. Individual well-tracer combinations that were not modeled are included in the table as blank rows.

\begin{tabular}{|c|c|c|c|c|c|c|c|c|c|c|c|}
\hline \multirow{2}{*}{ Model } & \multirow[b]{2}{*}{ Well } & \multirow{2}{*}{$\begin{array}{r}\text { Pathlength } \\
(\mathrm{m})\end{array}$} & \multirow[b]{2}{*}{ Tracer } & \multirow[b]{2}{*}{$\varepsilon$} & \multirow{2}{*}{$\begin{array}{c}\text { Mass } \\
\text { Diff }\end{array}$} & \multicolumn{2}{|c|}{ Parameter } & \multirow{2}{*}{$\begin{array}{l}\text { Delay } \\
(\mathrm{min})\end{array}$} & \multirow{2}{*}{$\begin{array}{l}\text { MRT } \\
(\min )\end{array}$} & \multirow{2}{*}{$\begin{array}{l}\text { Variance } \\
\left(\min ^{2}\right)\end{array}$} & \multirow{2}{*}{$\begin{array}{l}\text { Velocity } \\
\left(\mathrm{ms}^{-1}\right)\end{array}$} \\
\hline & & & & & & 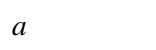 & $b$ & & & & \\
\hline \multirow[t]{8}{*}{$\operatorname{Exp}$} & 1 & 9.1 & $\begin{array}{c}\mathrm{EC} \\
\mathrm{Cl}^{-}\end{array}$ & 0.86 & 0.049 & $2.0 \times 10^{-4}$ & - & 380 & $4.2 \times 10^{4}$ & $2.1 \times 10^{8}$ & $3.6 \times 10^{-6}$ \\
\hline & 2 & 13.9 & $\begin{array}{l}\mathrm{EC} \\
\mathrm{Cl}^{-}\end{array}$ & 0.24 & -0.204 & $1.0 \times 10^{-4}$ & - & 39 & $8.3 \times 10^{4}$ & $8.3 \times 10^{8}$ & $2.8 \times 10^{-6}$ \\
\hline & 3 & 17.1 & $\mathrm{EC}$ & 0.95 & 0.008 & $3.0 \times 10^{-4}$ & - & 500 & $2.8 \times 10^{4}$ & $1.1 \times 10^{7}$ & $1.0 \times 10^{-5}$ \\
\hline & 15 & 10.9 & $\begin{array}{l}\mathrm{EC} \\
\mathrm{Cl}^{-}\end{array}$ & 0.04 & -0.103 & $1.5 \times 10^{-5}$ & - & 195 & $5.4 \times 10^{5}$ & $3.5 \times 10^{10}$ & $3.4 \times 10^{-7}$ \\
\hline & 16 & 8.2 & $\mathrm{EC}$ & & & & & & & & \\
\hline & 17 & 11.6 & $\begin{array}{l}\mathrm{EC} \\
\mathrm{Cl}^{-}\end{array}$ & & & & & & & & \\
\hline & 19 & 15.5 & $\mathrm{EC}$ & 0.80 & 0.044 & $1.6 \times 10^{-4}$ & - & 0 & $5.1 \times 10^{4}$ & $3.1 \times 10^{8}$ & $5.1 \times 10^{-6}$ \\
\hline & & Mean & & 0.55 & -0.004 & & & 219 & $1.6 \times 10^{5}$ & $7.3 \times 10^{9}$ & $4.4 \times 10^{-6}$ \\
\hline \multirow[t]{8}{*}{ Gamma } & 1 & 9.1 & $\begin{array}{l}\mathrm{EC} \\
\mathrm{Cl}^{-}\end{array}$ & 0.87 & 0.020 & $1.1 \times 10^{5}$ & $6.9 \times 10^{-1}$ & 438 & $6.3 \times 10^{5}$ & $6.7 \times 10^{10}$ & $2.4 \times 10^{-7}$ \\
\hline & 2 & 13.9 & $\begin{array}{l}\mathrm{EC} \\
\mathrm{Cl}^{-}\end{array}$ & 0.85 & -0.123 & $2.7 \times 10^{-2}$ & $7.1 \times 10^{0}$ & 32 & $2.2 \times 10^{3}$ & $7.9 \times 10^{4}$ & $1.1 \times 10^{-4}$ \\
\hline & 3 & 17.1 & $\mathrm{EC}$ & 0.95 & 0.020 & $3.8 \times 10^{-5}$ & $8.2 \times 10^{-1}$ & 636 & $1.8 \times 10^{5}$ & $4.7 \times 10^{9}$ & $1.6 \times 10^{-6}$ \\
\hline & 15 & 10.9 & $\begin{array}{l}\mathrm{EC} \\
\mathrm{Cl}^{-}\end{array}$ & 0.04 & -0.083 & $3.0 \times 10^{-5}$ & $1.3 \times 10^{0}$ & 21 & $3.5 \times 10^{5}$ & $1.2 \times 10^{10}$ & $5.2 \times 10^{-7}$ \\
\hline & 16 & 8.2 & $\mathrm{EC}$ & & & & & & & & \\
\hline & 17 & 11.6 & $\begin{array}{l}\mathrm{EC} \\
\mathrm{Cl}^{-}\end{array}$ & & & & & & & & \\
\hline & 19 & 15.5 & $\mathrm{EC}$ & 0.83 & -0.007 & $3.9 \times 10^{-5}$ & $1.2 \times 10^{0}$ & 24 & $2.0 \times 10^{6}$ & $7.3 \times 10^{11}$ & $1.3 \times 10^{-7}$ \\
\hline & & Mean & & 0.71 & -0.003 & & & 230 & $6.3 \times 10^{5}$ & $1.6 \times 10^{11}$ & $2.2 \times 10^{-5}$ \\
\hline
\end{tabular}

assumptions of transport mechanisms, which in the field are usually unknown or unknowable (Jury, 1982). A linear system model lumps complex processes into a probabilistic function of time or flow, so even though pressure or tracer residence time is largely dependent on mechanisms such as soil hydraulic conductivity and flow paths, we need not measure these mechanisms directly to infer their influence on transport (Sardin et al., 1991). Conclusions from this study are based on this key assumption. Confidence in modeled residence time distributions is limited by the accuracy and resolution of the defined input and response functions. One potentially important source of error is in the accuracy of the baselines defined for tracer and pressure wave response functions. The model fits of the tails of the pressure wave breakthrough curves (late-time data) were most sensitive to interpretation. For tracer modeling, head differential time stopped when the reservoir drained, so we did not capture the tails of the breakthrough curves, and the shape of tracer response curves is less sensitive to interpretation.

Residence time distributions of tracer and pressure transport at small imposed gradients provide representative estimates of spatially variable flow rates and mechanisms in natural levee sediments, because hydraulic gradients in lowland riverine wetlands tend to be ephemeral and small. Although the mesoscale variation of chemical responses to forcing events was large, the magnitude of variability and its causes are more than can be quantified from our study. Transport in field soils is affected by multiple factors. Spatial variability in chemical response may be partially attributed to antecedent moisture conditions (Flury et al., 1994) and microtopography (Weiler and Naef, 2003), which affect infiltration patterns and flow paths. Temporal variability in tracer responses between tests reflects the dynamic nature of infiltration and transport mechanisms, which are affected by spatially variable and dynamic water table, vegetation changes, and burrowing organisms in the subsurface. Spatial and temporal variability of subsurface hydrochemistry likely reflects all of these mechanisms to some extent.

Differences in both pressure and tracer transport between the two tests were at least partially attributable to soil moisture and water table elevation differences. We modeled residence time distributions during a period when the reservoir contained surface water, and this occurred after the soil beneath the reservoir became satiated (if not saturated). Larger time delays for the salt-added test, which occurred when stream stage was low, were caused by water filling up the 
Table 5. Modeling results of tracer transport for salt-added test. Negative values of Mass Diff (proportional mass difference) indicate greater mass in the model than in the observations. Individual well-tracer combinations that were not modeled are included in the table as blank rows.

\begin{tabular}{|c|c|c|c|c|c|c|c|c|c|c|c|}
\hline \multirow[b]{2}{*}{ Model } & \multirow[b]{2}{*}{ Well } & \multirow{2}{*}{$\begin{array}{r}\text { Pathlength } \\
(\mathrm{m})\end{array}$} & \multirow[b]{2}{*}{ Tracer } & \multirow[b]{2}{*}{$(\varepsilon)$} & \multirow{2}{*}{$\begin{array}{l}\text { Mass } \\
\text { Diff }\end{array}$} & \multirow{2}{*}{\multicolumn{2}{|c|}{$\begin{array}{c}\text { Parameter } \\
b\end{array}$}} & \multirow{2}{*}{$\begin{array}{l}\text { Delay } \\
(\mathrm{min})\end{array}$} & \multirow{2}{*}{$\begin{array}{l}\text { MRT } \\
(\min )\end{array}$} & \multirow{2}{*}{$\begin{array}{l}\text { Variance } \\
\left(\min ^{2}\right)\end{array}$} & \multirow{2}{*}{$\begin{array}{l}\text { Velocity } \\
\left(\mathrm{ms}^{-1}\right)\end{array}$} \\
\hline & & & & & & & & & & & \\
\hline \multirow[t]{12}{*}{ Exp } & 1 & 9.1 & $\mathrm{EC}$ & & & & & & & & \\
\hline & & & $\mathrm{Cl}^{-}$ & 0.85 & 0.058 & $6.9 \times 10^{-1}$ & - & 128 & $1.3 \times 10^{2}$ & $3.0 \times 10^{0}$ & $1.2 \times 10^{-3}$ \\
\hline & 2 & 13.9 & $\mathrm{EC}$ & 0.99 & 0.002 & $4.7 \times 10^{-1}$ & - & 160 & $1.6 \times 10^{2}$ & $6.6 \times 10^{0}$ & $1.4 \times 10^{-3}$ \\
\hline & & & $\mathrm{Cl}^{-}$ & 0.91 & 0.029 & $4.4 \times 10^{-1}$ & - & 74 & $7.7 \times 10^{1}$ & $7.4 \times 10^{0}$ & $3.0 \times 10^{-3}$ \\
\hline & 3 & 17.1 & EC & & & & & & & & \\
\hline & 15 & 10.9 & $\mathrm{EC}$ & 0.73 & 0.049 & $1.3 \times 10^{0}$ & - & 98 & $9.9 \times 10^{1}$ & $8.6 \times 10^{-1}$ & $1.9 \times 10^{-3}$ \\
\hline & & & $\mathrm{Cl}^{-}$ & 0.78 & 0.045 & $9.9 \times 10^{-1}$ & - & 98 & $9.9 \times 10^{1}$ & $1.4 \times 10^{0}$ & $1.8 \times 10^{-3}$ \\
\hline & 16 & 8.2 & $\mathrm{EC}$ & & & & & & & & \\
\hline & 17 & 11.6 & $\mathrm{EC}$ & 0.95 & -0.051 & $2.7 \times 10^{-5}$ & - & 14 & $5.2 \times 10^{4}$ & $1.9 \times 10^{9}$ & $3.7 \times 10^{-6}$ \\
\hline & & 15.5 & $\mathrm{Cl}^{-}$ & 0.94 & 0.066 & $4.6 \times 10^{-5}$ & - & 116 & $3.1 \times 10^{4}$ & $4.8 \times 10^{8}$ & $6.1 \times 10^{-6}$ \\
\hline & 19 & & $\mathrm{EC}$ & 0.52 & 0.022 & $2.8 \times 10^{-6}$ & - & 7 & $5.2 \times 10^{5}$ & $1.9 \times 10^{11}$ & $5.0 \times 10^{-7}$ \\
\hline & & Mean & & 0.83 & 0.015 & & & 70 & $7.5 \times 10^{4}$ & $2.4 \times 10^{10}$ & $1.2 \times 10^{-3}$ \\
\hline \multirow[t]{12}{*}{ Gamma } & 1 & 9.1 & $\mathrm{EC}$ & & & & & & & & \\
\hline & & & $\mathrm{Cl}^{-}$ & 0.96 & 0.001 & $2.5 \times 10^{-5}$ & $4.2 \times 10^{-1}$ & 71 & $2.4 \times 10^{4}$ & $9.6 \times 10^{8}$ & $6.2 \times 10^{-6}$ \\
\hline & 2 & 13.9 & $\mathrm{EC}$ & 0.99 & 0.029 & $2.0 \times 10^{-8}$ & $4.5 \times 10^{-3}$ & 160 & $3.3 \times 10^{5}$ & $1.6 \times 10^{13}$ & $7.1 \times 10^{-7}$ \\
\hline & & & $\mathrm{Cl}^{-}$ & 0.90 & 0.013 & $8.9 \times 10^{-6}$ & $4.8 \times 10^{-3}$ & 75 & $8.5 \times 10^{2}$ & $8.7 \times 10^{7}$ & $2.7 \times 10^{-4}$ \\
\hline & 3 & 17.1 & $\mathrm{EC}$ & & & & & & & & \\
\hline & 15 & 10.9 & $\mathrm{EC}$ & 0.90 & -0.006 & $6.6 \times 10^{-7}$ & $4.7 \times 10^{-1}$ & 32 & $1.0 \times 10^{6}$ & $1.6 \times 10^{12}$ & $1.8 \times 10^{-7}$ \\
\hline & & & $\mathrm{Cl}^{-}$ & 0.54 & -0.148 & $1.9 \times 10^{-6}$ & $4.2 \times 10^{-1}$ & 145 & $1.5 \times 10^{2}$ & $3.1 \times 10^{-2}$ & $1.3 \times 10^{-3}$ \\
\hline & 16 & 8.2 & $\mathrm{EC}$ & & & & & & & & \\
\hline & 17 & 11.6 & $\mathrm{EC}$ & 0.97 & -0.010 & $1.6 \times 10^{-4}$ & $1.1 \times 10^{0}$ & 38 & $9.8 \times 10^{3}$ & $6.1 \times 10^{7}$ & $2.0 \times 10^{-5}$ \\
\hline & & & $\mathrm{Cl}^{-}$ & 0.99 & 0.025 & $6.4 \times 10^{-5}$ & $8.8 \times 10^{-1}$ & 101 & $2.0 \times 10^{4}$ & $3.0 \times 10^{8}$ & $9.9 \times 10^{-6}$ \\
\hline & 19 & 15.5 & $\mathrm{EC}$ & 0.53 & 0.022 & $3.9 \times 10^{-5}$ & $1.2 \times 10^{0}$ & 4 & $4.5 \times 10^{4}$ & $1.2 \times 10^{9}$ & $5.7 \times 10^{-6}$ \\
\hline & & Mean & & 0.83 & 0.032 & & & 87 & $1.9 \times 10^{5}$ & $2.6 \times 10^{12}$ & $8.2 \times 10^{-6}$ \\
\hline
\end{tabular}

unsaturated soil volume as it flowed toward the wells. In the absence of soil moisture measurements, saturation of the soils is our best assumption, and any deviations from this condition were likely insignificant given the scale of measurement. Also, we can reasonably assume that transport occurred in lower layers of the soil when the water table was lower, and preferential flow may have occurred at the interface of the clay layer (Fig. 2), a phenomenon recognized in other natural systems (Haria et al., 1994). Higher stream stage during the no-salt test yielded a smaller hydraulic gradient than for the salt-added test when stream stage was lower (Table 1). The effect of a smaller hydraulic gradient is to decrease transport rates, which was generally the case for tracer velocities but not pressure velocities (Tables 2-5). In this work, the number of experiments was insufficient to draw correlations between varying initial states and connectivity mechanisms, but the effect of variable environmental conditions on the magnitude of preferential flow through natural levees is a potential direction for future work.

Overall, behaviors of EC and chloride tracers were difficult to reconcile. In our simple conceptual model, input causes a shift toward either old or new water chemistry. However, results suggest both new and old water may have arrived simultaneously by their respective mechanisms of bypass and matrix flow given the inhomogeneous and layered nature of alluvial soils. Lacking additional independent tracers, we were unable to separate water sources and resolve incongruities. During the salt-added test, EC and chloride varied apparently independently despite the fact that the two tracers were intrinsically related; the high EC in the reservoir water was a direct result of added $\mathrm{KCl}$. With the limited data set, we can only postulate whether instrument sensitivities or hydrochemical processes might have produced these results. For example, lack of correlation between EC and chloride data may have occurred if there was stratification of water during the salt-added test, either from chemical variability of laterally infiltrating soil water or from denser, KCl-laden water at the bottom of some wells; EC sensors were situated approximately $35 \mathrm{~cm}$ above chloride sensors in the wells. A process-based explanation is that multiple inflection points are an expression of antecedent spatial variability of hydrochemistry, which has been described by other authors (e.g., Lischeid et al., 2002).

Effective hydraulic conductivities $(K)$ seemed unrealistically high in some cases. Typical $K$ values for the soil types encountered are between $10^{-5}$ and $10^{0} \mathrm{~m} \mathrm{~d}^{-1}$ (Bear, 1972), 


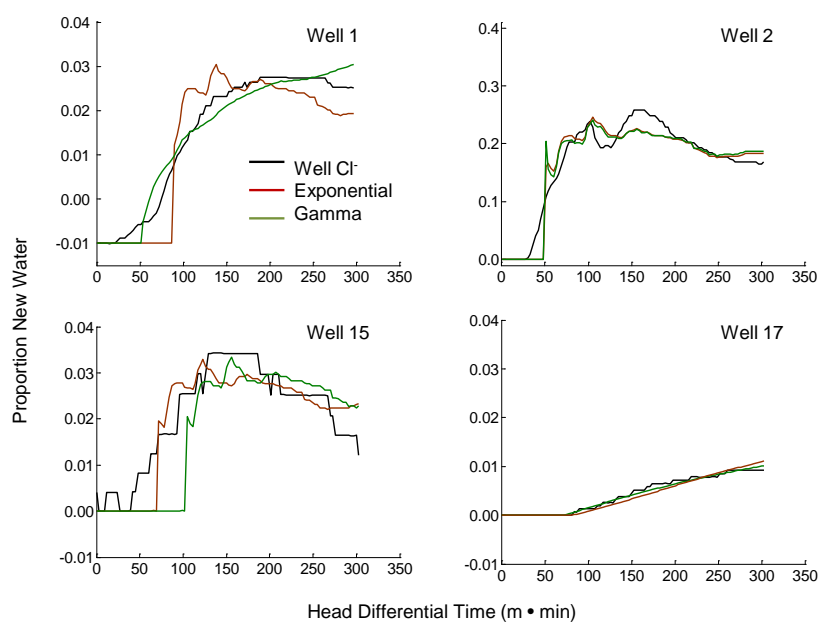

Fig. 9. Optimized models of chloride truncated at the end of head differential time for salt-added test. Well 2 is displayed on a largerscale axis because of larger-scale response.

which is lower by several orders of magnitude than our findings: $10^{-1}$ to $10^{3} \mathrm{~m} \mathrm{~d}^{-1}$. One potential source of error lies in estimated path lengths, which were the distances from the areal center of the reservoir to each well. Actual path lengths may have begun at the closest edge of the pool in the reservoir but were impractical to estimate, because the location of that edge varied in time and in relation to each well. As a result, because our straight-line path lengths may be overestimates, the estimates of hydraulic conductivity may also be overestimates. In calculating $K$ according to Eq. (6), the estimated path lengths are squared, so small differences in pathlength may account for as much as an order of magnitude in the calculated $K$. However, our estimates of pathlength also neglect tortuosity of flow paths, which would lengthen actual flow paths.

\subsection{Understanding transport mechanisms}

Although we cannot quantify preferential flow, field-scale variability in tracer versus pressure RTDs provides a framework for conceptualizing connectivity through natural levees. Shorter residence times and faster transport velocities of tracer in some wells suggest preferential flow, and spatial disparity in tracer mass recovery (Fig. 10) suggests that some wells were more directly connected to event water. The greater spatial variability of tracer RTDs in comparison to pressure RTDs indicates multiple functioning mechanisms of hydraulic response within the natural levee. Differences between pressure and tracer RTDs reinforce the importance of comparing the two measures of transport when characterizing subsurface connectivity. Optimized pressure transport models described a system of rapid response and relatively little spatial variability of residence time as compared to optimized tracer transport models. In agreement with other
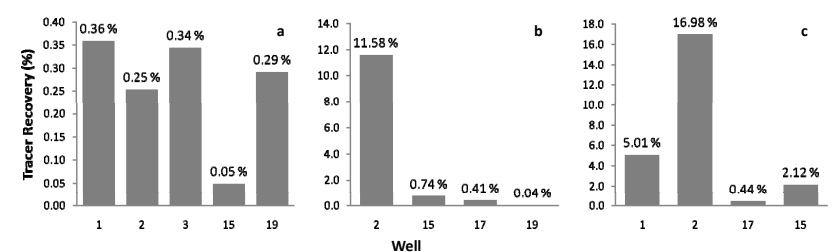

Fig. 10. Mass recovery of tracer for no-salt test EC (a), salt-added test EC (b), and salt-added test chloride (c).

recent studies (Knudby and Carrera, 2006), early arrival of tracer occurred within the same timescale (minutes to a few hours) as the average linear velocity of the groundwater.

Subsurface connections between backswamps and stream channels may have significant biogeochemical implications for riverine wetlands. Although we recognize the limitations of $K$ estimated from modeled transport rates, our findings imply that flow through macropores, sand lenses, and other mechanisms of preferential flow occurs at rates much greater than bulk soil characteristics suggest. At stream margins, biogeochemical hot spots form where hydrological flow paths converge with other flow paths or substrates containing complementary reactants (Triska et al., 1993; McClain et al., 2003), and such hot spots have been specifically observed in natural levees (Johnston et al., 2001). In a riverine wetland, exchange of relatively oxygenated surface water with subsurface flow may provide opportunities for aerobic respiration in an otherwise anaerobic environment and may deliver nutrients carried by the stream to anaerobic areas where denitrification can occur. In this way, preferential flow paths in natural levees of fine-grained floodplains may provide biogeochemically important vectors of water and solutes in a system with otherwise little subsurface exchange.

The appropriate scale for measuring hydraulic properties is largely dependent upon the characteristics of the system. Given the ubiquity of highly variable hydraulic conductivity in field soils, understanding bulk $K$ requires knowing the probability distribution of $K$ as well as the arrangement of high and low $K$ areas, because effective transport is greater when high $K$ areas are connected (Ronayne et al., 2010). This may be particularly important in our fluvial system where the primary transport vectors are likely either discrete high- $K$ layers deposited in specific flood events or macropores. The high heterogeneity of soil properties in both space and time is an important consideration when estimating the bulk $K$ of a field soil and affects the scale at which $K$ should be measured. Situated somewhere between a catchment scale and a soil core scale, our experiments can be considered a mesoscale study. If transport vectors that control hydrologic connectivity between wetlands and rivers are in this intermediate size range, understanding hydrologic processes at this scale is important to conceptualize the role of natural levees in floodplains. Additionally, because extrapolating hydraulic properties to scales outside those in which they were directly 
measured is problematic, these results may be particularly valuable as they are directly relevant to a scale that is often the focus of management applications.

\section{Conclusions}

In fine-grained floodplains where surface connections between rivers and wetlands are often limited, subsurface exchange through natural levees via preferential flow can be an important means of connectivity. In this study, the linear system model allowed analysis of variability of transport rates of pressure and tracer at a mesoscale. The spatial mean velocity of pressure transport was faster than the mean velocity of tracer transport by two orders of magnitude $\left(1.7 \times 10^{-2}\right.$ and $4.6 \times 10^{-4} \mathrm{~m} \mathrm{~s}^{-1}$, respectively), and the variance of pressure velocities was less than the variance of tracer velocities by seven orders of magnitude $\left(1.4 \times 10^{4} \mathrm{~min}^{2}\right.$ and $7.9 \times 10^{11}$ $\min ^{2}$, respectively). Higher spatial variability of tracer versus pressure residence time distributions indicates different functioning mechanisms of mass versus energy transport and suggests preferential flow. The effective hydraulic conductivities we found, which ranged in magnitude from $10^{-1}$ to $10^{3} \mathrm{~m} \mathrm{~d}^{-1}$, were much higher than would be predicted by soil texture and likely represent the small fraction of bulk sediment volume that is most conductive. Especially in this fine-grained system, preferential flow paths are a controlling mechanism of water and solute exchange through natural levees. These findings are important for future studies of water and solute cycling in riverine wetlands, and rates of exchange may be particularly useful for modeling water and nutrient budgets in similar systems.

Acknowledgements. The authors extend sincere thanks to those who contributed substantially to this work: Gregory Badon and Evan Rinehart for field and instrumentation assistance; Magdi Selim, Michael Gooseff, and William Blanford who individually offered early advice on experimental design; Genevieve Ali and several anonymous reviewers who provided constructive criticism of the manuscript; and the US Army Corps of Engineers for funding the research.

Edited by: H. H. G. Savenije

\section{References}

Amoros, C. and Bornette G.: Connectivity and biocomplexity in waterbodies of riverine floodplains, Freshwater Biol., 47, 761-776, 2002.

Asano, Y., Uchida, T., and Ohte, N.: Residence times and flow paths of water in steep unchannelled catchments, Tanakami, Japan, J. Hydrol., 261, 173-192, 2002.

Aslan, A., Autin, W. J., and Blum, M. D.: Causes of river avulsion: insights from the late holocene avulsion history of the Mississippi River, USA, J. Sediment. Res., 75, 650-664, 2005.
Barron, A.: Acidification of poorly drained backswamp soils in the Mississippi River floodplain due to reduced sulphur oxidation, Master of Science, Department of Agronomy, Louisiana State University, 103 pp., 1996.

Bear, J.: Dynamics of fluids in porous media, Elsevier, Mineola, NY, 764 pp., 1972.

Beven, K.: Kinematic subsurface stormflow, Water Resour. Res., 17, 1419-1424, 1981.

Bracken, L. J. and Croke J.: The concept of hydrological connectivity and its contribution to understanding runoffdominated geomorphic systems, Hydrol. Process., 21, 17491763, doi:10.1002/hyp.6313, 2007.

Bradley, C.: Simulation of the annual water table dynamics of a floodplain wetland, Narborough Bog, UK, J. Hydrol., 261, 150-172, 2002.

Cazanacli, D. and Smith, N. D.: A study of morphology and texture of natural levees - Cumberland Marshes, Saskatchewan, Canada, Geomorphology, 25, 43-55, 1998.

Chazarenc, F., Merlin, G., and Gonthier, Y.:, Hydrodynamics of horizontal subsurface flow constructed wetlands, Ecol. Eng., 21, 165-173, doi:10.1016/j.ecoleng.2003.12.001, 2003.

Church, M. R.: Hydrochemistry of forested catchments, Annu. Rev. Earth Pl. Sc., 25, 23-59, 1997.

Dooge, J.: Linear theory of hydrologic systems, Agricultural Research Service, US Dept. of Agriculture, Washington, DC, 327 pp., 1973.

Duffy, C. J. and Gelhar L. W.: A frequency-domain approach to water-quality modeling in groundwater - theory, Water Resour. Res., 21, 1175-1184, 1985.

Elci, A. and Molz F. J: Identification of lateral macropore flow in a forested riparian wetland through numerical simulation of a subsurface tracer experiment, Water Air Soil Poll., 197, 149164, doi:10.1007/s11270-008-9798-5, 2009.

Fisk, H. N.: Geological investigation of the atchafalaya basin and the problem of Mississippi River diversion Rep., US Army Corps Engineers, Mississippi River Committee, Vicksburg, Mississippi, 1952.

Flury, M., Fluhler, H., Jury, W. A., and Leuenberger, J.: Suseptiblity of soils to preferential flow of water - a field study, Water Resour. Res., 30, 1945-1954, 1994.

Fuchs, J. W., Fox, G. A., Storm, D. E., Penn, C. J., and Brown, G. O.: Subsurface transport of phosphorus in riparian floodplains: influence of preferential flow paths, J. Environ. Qual., 38, 473-484, doi:10.2134/jeq2008.0201, 2009.

Haria, A. H., Johnson, A. C., Bell, J. P., and Batchelor, C. H.: Water movement and isoproturon behaviour in a drained heavy clay soil: 1. preferential flow processes, J. Hydrol., 163, 203-216, 1994.

Harvey, J. W., Chambers, R. M., and Hoelscher, J. R.: Preferential flow and segregation of porewater solutes in wetland sediment, Estuaries, 18, 568-578, 1995.

Hewlett, J. D.: Principles of Forest Hydrology, The University of Georgia Press, Athens, 183 pp., 1982.

Hupp, C. R.: Hydrology, geomorphology and vegetation of coastal plain rivers in the South-Eastern USA, Hydrol. Process., 14, 2991-3010, 2000.

Hupp, C. R., Demas, C. R., Kroes, D. E., Day, R. H., and Doyle T. W.: Recent sedimentation patterns within the central Atchafalaya Basin, Louisiana, Wetlands, 28, 125-140 2008. 
Johnston, C. A., Bridgham, S. D., and Schubauer-Berigan, J. P.: Nutrient dynamics in relation to geomorphology of riverine wetlands, Soil Sci. Soc. Am. J., 65, 557-577, 2001.

Jones, J. P., Sudicky, E. A., Brookfield, A. E., and Park, Y. J.: An assessment of the tracer-based approach to quantifying groundwater contributions to streamflow, Water Resour. Res., 42, W02407, doi:10.1029/2005WR004130, 2006.

Jones, K. L., Poole, G. C., Woessner, W. W., Vitale, M. V., Boer, B. R., O’Daniel, S. J., Thomas, S. A., and Geffen, B. A.: Geomorphology, hydrology, and aquatic vegetation drive seasonal hyporheic flow patterns across a gravel-dominated floodplain, Hydrol. Process., 22, 2105-2113, doi:10.1002/hyp.6810, 2008

Jury, W. A.: Simulation of solute transport using a transfer-function model, Water Resour. Res., 18, 363-368, 1982.

Jury, W. A., Sposito, G., and White R. E.: A transfer-function model of solute transport through soil, 1. fundamental concepts, Water Resour. Res., 22, 243-247, 1986.

Kabat, P., Hutjes, R. W. A., and Feddes, R. A.: The scaling characteristics of soil parameters: from plot scale heterogeneity to subgrid parameterization, J. Hydrol., 190, 363-396, 1997.

Kirchner, J. W.: Getting the right answers for the right reasons: linking measurements, analyses, and models to advance the science of hydrology, Water Resour. Res., 42, W03S04, doi:10.1029/2005wr004362, 2006.

Knudby, C. and Carrera J.: On the use of apparent hydraulic diffusivity as an indicator of connectivity, J. Hydrol., 329, 377-389, doi:10.1016/j.jhydrol.2006.02.026, 2006.

Lagarias, J. C., Reeds, J. A., Wright, M. H., and Wright, P. E: Convergence properties of the Nelder-Mead simplex method in low dimensions, Siam J. Optimiz., 9, 112-147, 1998.

Legout, A., Legout, C., Nys, C., and Dambrine, E.: Preferential flow and slow convective chloride transport through the soil of a forested landscape (Fougeres, France), Geoderma, 151, 179190, doi:10.1016/j.geoderma.2009.04.002, 2009.

Lewandowski, J., Lischeid, G., and Nutzmann, G.: Drivers of water level fluctuations and hydrological exchange between groundwater and surface water at the lowland river Spree (Germany): field study and statistical analyses, Hydrol. Process., 23, 2117-2128, doi:10.1002/hyp.7277, 2009.

Lischeid, G., Kolb A., and Alewell, C.: Apparent translatory flow in groundwater recharge and runoff generation. J. Hydrol., 265, 195-211, 2002.

Malard, F., Tockner, K., Dole-Olivier, M.-J., and Ward, J. V.: A landscape perspective of surface-subsurface hydrological exchanges in river corridors, Freshwater Biol., 47, 621-640, 2002.

Maloszewski, P. and Zuber, A.: A general lumped parameter model for the interpretation of tracer data and transit time calculation in hydrologic systems - comments, J. Hydrol., 204, 297-300, 1998.

McClain, M. E., Boyer, E. W., Dent, C. L., Gergel, S. E., Grimm, N. B., Groffman, P. M., Hart, S. C., Harvey, J. W., Johnston, C. A., Mayorga, E., McDowell, W. H., and Pinay, G.: Biogeochemical hot spots and hot moments at the interface of terrestrial and aquatic ecosystems, Ecosystems, 6, 301-312, doi:10.1007/s10021-003-0161-9, 2003.

McDonnell, J. J., Sivapalan, M., Vaché, K., Dunn, S., Grant, G., Haggerty, R., Hinz, C., Hooper, R., Krichner, J., Roderick, M. L., Selker, J., and Weiler, M.: Moving beyond heterogeneity and process, 43, W07301, doi:10.1029/2006wr005467, 2007.
McGuire, K. J. and McDonnell J. J.: A review and evaluation of catchment transit time modeling, J. Hydrol., 330, 543-563, doi:10.1016/j.jhydrol.2006.04.020, 2006.

McGuire, K. J., DeWalle, D. R., and Gburek, W. J.: Evaluation of mean residence time in subsurface waters using oxygen-18 fluctuations during drought conditions in the mid-appalachians, J. Hydrol., 261, 132-149 2002.

Nash, J. E. and Sutcliffe J. V.: River flow forecasting through conceptual models, i, a discussion of principles, J. Hydrol., 10, 282 290, 1970.

Nield, D. A.: Connectivity and effective hydraulic conductivity, Transport Porous Med., 74, 129-132, 2008

Noguchi, S., Tsuboyama, Y., Sidle, R. C., and Hosoda, I.: Morphological characteristics of macropores and the distribution of preferential flow pathways in a forested slope segment, Soil Sci. Soc. Am. J., 63, 1413-1423, 1999.

Rasmussen, T. C., Baldwin, R. H., Dowd, J. F., and Williams, A. G.: Tracer vs. pressure wave velocities through unsaturated saprolite, Soil Sci. Soc. Am. J., 64, 75-85, 2000.

Rassam, D. W., Fellows, C. S., De Hayr, R., Hunter, H., and Bloesch, P.: The hydrology of riparian buffer zones; two case studies in an ephemeral and a perennial stream, J. Hydrol., 325, 308-324, doi:10.1016/j.jhydrol.2005.10.023, 2006.

Ronayne, M. J., Gorelick, S. M., and Zheng, C. M.: Geological modeling of submeter scale heterogeneity and its influence on tracer transport in a fluvial aquifer, Water Resour. Res., 46, W10519, doi:10.1029/2010wr009348, 2010.

Sabo, M. J., Bryan, C. F., Kelso, W. E., and Rutherford, A.: Hydrology and aquatic habitat characteristics of a riverine swamp: I. influence of flow on water temperature and chemistry, Regul. River., 15, 505-523, 1999.

Sardin, M., Schweich, D., Leij, F. J., and Vangenuchten, M. T.: Modeling the nonequilibrium transport of linearly interacting solutes in porous-media - a review, Water Resour. Res., 27, 2287 2307, 1991.

Seyfried, M. S. and Wilcox, B. P.: Scale and the nature of spatial variability - field examples having implication for hydrologic modeling, Water Resour. Res., 31, 173-184, 1995.

Sidle, R. C., Noguchi, S., Tsuboyama, Y., and Laursen, K.: A conceptual model of preferential flow systems in forested hillslopes: evidence of self-organization, Hydrol. Process., 15, 1675-1692, 2001.

Soulsby, C., Piegat, K., Seibert, J., and Tetzlaff, D.: Catchmentscale estimates of flow path partitioning and water storage based on transit time and runoff modelling, Hydrol. Process., 25, 3960 3976, doi:10.1002/hyp.8324, 2011.

Triska, F. J., Duff, J. H., and Avanzino, R. J.: The role of water exchange between a stream shcannel and its hyporheic zone in a nitrogen cycling at the terrestrial aquatic aquatic interface, Hydrobiologia, 251, 167-184, 1993.

Tromp-van Meerveld, H. J., and McDonnell, J. J.: Threshold relations in subsurface stormflow: 2. The fill and spill hypothesis, Water Resour. Res., 42, W02411, doi:10.1029/2004WR003800, 2006.

Tye, R. S. and Coleman, J. M.: Depositional processes and stratigraphy of fluvially dominated lacustrine deltas - Mississippi delta plain, J. Sediment. Petrol., 59, 973-996, 1989. 
Verma, P., Yeates, J., and Daly, E.: A stochastic model describing the impact of daily rainfall depth distribution on the soil water balance, Adv. Water Resour., 34, 1039-1048, doi:10.1016/j.advwatres.2011.05.013, 2011.

Weiler, M. and Naef, F.: Simulating surface and subsurface initiation of macropore flow, J. Hydrol., 273, 139-154, 2003.
Zhang, B., Tang, J. L., Gao, C., and Zepp, H.: Subsurface lateral flow from hillslope and its contribution to nitrate loading in streams through an agricultural catchment during subtropical rainstorm events, Hydrol. Earth Syst. Sci., 15, 3153-3170, doi:10.5194/hess-15-3153-2011, 2011. 